Western University

Scholarship@Western

Oncology Publications

Oncology Department

$10-2011$

\title{
Lung Cancer Brachytherapy: Robotics-Assisted Minimally Invasive Approach
}

Edward Yu

The University of Western Ontario

Craig Lewis

The University of Western Ontario

Ana Luisa Trejos

The University of Western Ontario

Rajni V. Patel

The University of Western Ontario

Richard A. Malthaner

The University of Western Ontario

Follow this and additional works at: https://ir.lib.uwo.ca/oncpub

Part of the Electrical and Computer Engineering Commons, Medical Biophysics Commons, and the Oncology Commons

Citation of this paper:

Yu, Edward; Lewis, Craig; Trejos, Ana Luisa; Patel, Rajni V.; and Malthaner, Richard A., "Lung Cancer Brachytherapy: RoboticsAssisted Minimally Invasive Approach" (2011). Oncology Publications. 77.

https://ir.lib.uwo.ca/oncpub/77 


\title{
Lung Cancer Brachytherapy: Robotics-Assisted Minimally Invasive Approach
}

\author{
Edward $\mathrm{Yu}^{*}, 1$, Craig Lewis ${ }^{1}$, Ana Luisa Trejos ${ }^{2,3}$, Rajni V. Patel ${ }^{2,3}$, and Richard A. Malthaner ${ }^{1,2}$ \\ ${ }^{I}$ The University of Western Ontario, London Health Science Center, Division of Radiation Oncology, 790 \\ Commissioners Road East, London, Ontario, N6A 4L6, Canada \\ ${ }^{2}$ Canadian Surgical Technologies and Advanced Robotics, Lawson Health Research Institute, 339 Windermere Road, \\ London, Ontario, N6A 5A5, Canada \\ ${ }^{3}$ Department of Electrical and Computer Engineering, The University of Western Ontario, 1151 Richmond Street North, \\ London, ON, N6A 5B9, Canada
}

\begin{abstract}
New technological concepts have been evolving to manage the relative poor prognosis of lung cancer. Brachytherapy is becoming an option for both unresectable and early resectable lung cancer. Three-dimensional ultrasound (US) of lung tumours and image-guided minimally invasive robotics-assisted brachytherapy are feasible for dosimetry planning and management of lung tumours. The present article reviews the current knowledge of lung brachytherapy and discusses its potential in future management of lung cancer.
\end{abstract}

Keywords: Brachytherapy, lung tumour, minimally invasive, robotics-assisted surgery and therapy.

\section{INTRODUCTION}

Lung cancer is the leading cause of cancer death in men, and has surpassed breast cancer as the most frequent cause of death in women [1]. Surgical resection is the treatment of choice, but only one third of patients who present with early disease are eligible for a curative resection [2]. Open surgery provides ready access and optimal visualization of body cavities, however, it has a higher rate of morbidity compared to minimally invasive techniques. Other options need to be developed. Brachytherapy is a form of radiation therapy delivered by the direct placement of a radioactive source into a tumour or tumour bed. It provides an option that avoids major surgery, chemotherapy, and is not susceptible to the uncertainty of tumour motion while the patient receives external beam radiation. It also avoids conventional multiple external beam radiation fractions that occur over several weeks. Brachytherapy also has theoretical advantages including: i) it is easily adapted to the shape and size of tumour, ii) it delivers a higher tumour dose compared to external beam irradiation, and iii) the delivered radiation dose decreases rapidly outside the treated tumour volume, significantly sparing the normal tissue in the tumour vicinity.

\section{LUNG CANCER BRACHYTHERAPY}

Endobronchial and/or intraoperative lung brachytherapy is effective and has a good curative potential in patients with localized tumours of small to moderate size, well defined and easily accessible. Large tumours, multiple lesions, or the presence of lymph node metastases precludes curative treatment by brachytherapy. In selected cases, quick and effective palliation may be obtained by an endobronchial outpatient procedure.

*Address correspondence to this author at the University of Western Ontario, London Health Science Center, Division of Radiation Oncology, 790 Commissioners Road East, London, Ontario, N6A 4L6, Canada;

Tel: 519-685-8650; E-mail: Edward.yu@lhsc.on.ca
Brachytherapy techniques and approaches can be tailored to the clinical situation and can be administered over a very short period of time (high dose rate), or over a protracted time (low dose rate). Table 1 shows the commonly use isotopes in brachytherapy.

There are two common brachytherapy techniques for lung cancer: Endobronchial Brachytherapy and Interstitial Brachytherapy. The details of these two techniques are discussed below.

\section{Endobronchial Brachytherapy}

Endobronchial treatment is the most common lung brachytherapy technique. Radiation therapy is delivered from within the trachea or bronchus lumen by placement of one or two afterloading applicators. The applicators, sometimes referred to as catheters, typically have a 5 or 6 French external diameter. A guidewire is often used to pass directly through the operating channel of a fibre optic bronchoscope and be threaded through the involved airway. Care must be taken to slowly advance the applicator over the guidewire, preferably under direct visual or fluoroscopic control. After placement of the brachytherapy catheter, the bronchoscope is removed and "dummy" seeds (an inactive strand of radioopaque marker pellets) are inserted within the applicator. An orthogonal set of chest radiographs (anterior-posterior and cross-table lateral) are obtained. The target is identified on the films using the visual information obtained that day by the bronchoscopist combined with previous radiological or bronchoscopic findings. The distal extent of the tumour cannot always be visualized by the bronchoscopist and must often be estimated from previous computerized tomography scans, chest radiographs, etc. Brachytherapy is delivered to the endobronchial tumour length with a $1-2 \mathrm{~cm}$ proximal and distal margin. The dummy seeds are then removed from the catheter and replaced with an inner applicator with radiation source of either Low Dose Rate (LDR) or High 
Table 1. Common Isotopes used in Brachytherapy

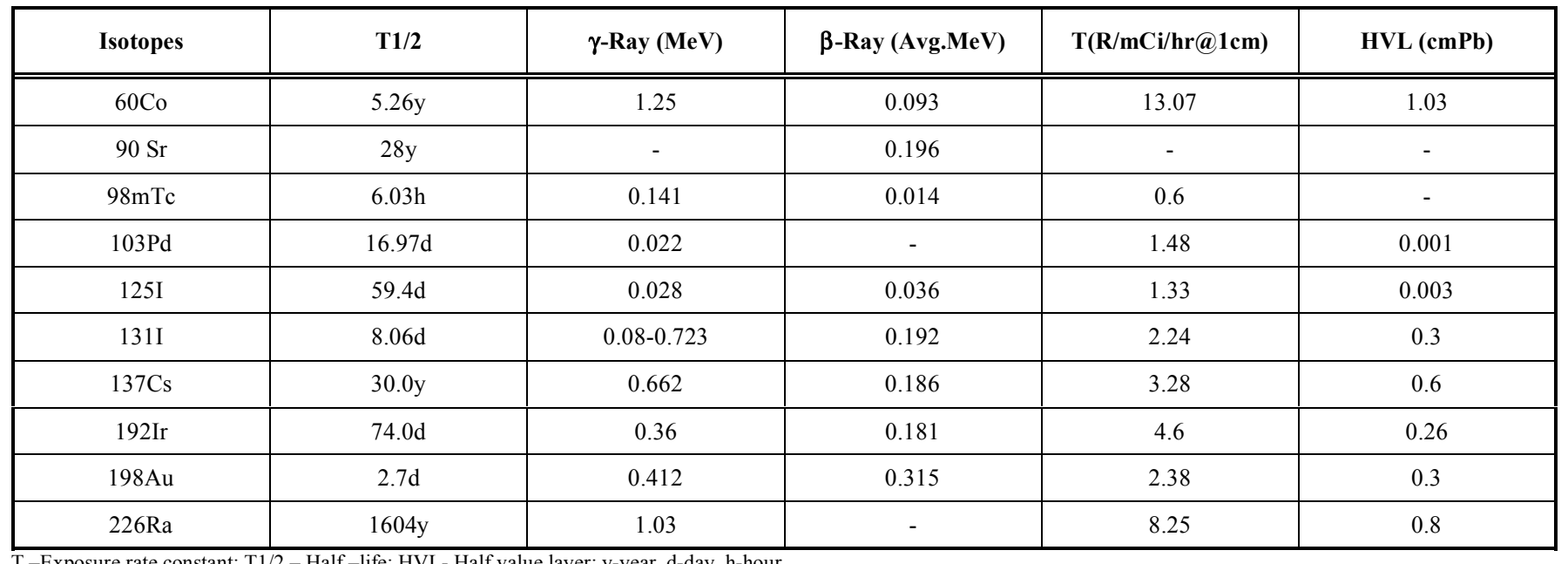

T-Exposure rate constant; T1/2 - Half-life; HVL- Half value layer; y-year, d-day, h-hour.

Dose Rate (HDR) inner applicator. HDR remote afterloading machines contain a microprocessor that controls the transfer of the source down the flexible inner applicator to the specified region, and withdraws it automatically into the machine when treatment is complete. Treatment is delivered in a shielded room where the patient and the patient's vital signs and oxygen saturation can be monitored from outside the room with the use of video equipment. The remote afterloading treatment can be interrupted at any time if necessary.

\section{Interstitial Brachytherapy}

Several investigators have described the technical aspects of permanent interstitial brachytherapy, the placement of radioactive source into the tumour or target region where no lumen exists [3-7]. This can be accomplished intraoperatively, transbronchially, or percutaneously. Isotopes such as Iodine (I-125), Palladium (Pd-103) and Gold (Au-198) which have low energy gamma rays, small physical size, and short half-lives are often used. Mick applicators are commercially available to insert the seeds manually one by one into the target region. However, the risk of subsequent seed movement has led many brachytherapists to suggest, depending on the clinical situation, that seeds be in the form of a strand with a Vicryl ${ }^{\mathbb{B}}$ carrier which can be woven into a Dexon ${ }^{\mathbb{B}}$ mesh and secured to the tumour bed [5]. Nori et al. [5] have described the intraoperative technique of sandwiching iodine seeds between sheets of Gelfoam and then securing these in place with Dexon ${ }^{\circledR} /$ Vicryl $^{\circledR}$ mesh. In their experience, the seeds have remained in site despite the fact that the mesh and Gelfoam are absorbed within the surrounding tissues within 6-8 weeks.

Brachytherapy can be given in either HDR or in LDR as presented below. A review the clinical results of brachytherapy is also presented.

\section{HDR Brachytherapy}

HDR brachytherapy has been defined as brachytherapy capable of delivering more than $12 \mathrm{~Gy} / \mathrm{h}(>0.2 \mathrm{~Gy} / \mathrm{min})$ [8].
The isotopes most commonly used include Cobalt (Co-60), Caesium (Cs-137), and Iridium (Ir-192). Endobronchial HDR brachytherapy uses a flexible bronchoscope to place an intraluminal treatment applicator at the location of the tumour to provide higher radiation dose at the center of the tumour than at the periphery. This reduces the effect of the radiation on the surrounding tissue [9]. HDR brachytherapy has been used as an alternative to, and in combination with, external beam radiation therapy for palliation of symptoms such as dyspnea, cough, chest pain, and hemoptysis in nonsmall cell lung cancer (NSCLC) [10]. Quality of life assessment in HDR has been reported in randomized trials including Langendijk et al. [11] the European Organization for Research and Treatment of Cancer (EORTC) general questionnaires, Sur et al. [12,13] the National Cancer Institute Common Toxicity Criteria, Stout et al. [14] Rotterdam Symptom Checklist and Hospital Anxiety and Depression scale. In general HDR relieves and improves symptoms of dyspnea, atelectasis, and chest pain. In particular HDR is most valuable in patients previously treated with external beam radiation therapy and symptomatic for recurrent disease due to endobronchial obstruction. The general recommended dose for HDR in symptom control is $1000 \mathrm{cGy}$ at $1 \mathrm{~cm}$ from central axis given in a single fraction, with $2 \mathrm{~cm}$ proximal and distal margin [10]. Most tumours either decreased in size or there was a reduction in pain. However, complications such as pneumothorax, and hemoptysis have been described [10].

An electromagnetic navigated bronchoscopic approach to a small peripheral tumour has recently been described by Harms et al. [15]. A single patient with medically inoperable NSCLC in the right upper lobe was treated with externalbeam radiotherapy (50 Gy) and navigated endoluminal brachytherapy (15 Gy). Bronchoscopy was performed with an electromagnetic navigation using a microsensor mounted on the tip of a dedicated catheter placed within the working channel of a bronchoscope. Endobronchial ultrasound (EBUS) was performed to confirm the exact position in the center of the lesion. HDR brachytherapy (370 GBq Ir-192) was applied. Complete remission was found during followup (12 months). HDR brachytherapy has also been delivered to lung cancers using a percutaneous route [16-20]. Ricke 
and coworkers [19] reported a pilot study of 30 patients with interstitial HDR brachytherapy. In their study cohort the maximum tumour size was $4 \mathrm{~cm}$ and the brachytherapy catheter was positioned under CT fluoroscopy. A single fraction of $20 \mathrm{~Gy}$ was delivered to the tumour. Although the follow up was short (median 5 months) local tumour control was $97 \%$. CT guided interstitial brachytherapy was safe.

Brachytherapy has been used by several investigators as a boost either before, during or after external beam radiation in the definitive treatment of unresectable NSCLC. The experience of HDR brachytherapy boost is extensive in the literature [21-27]. Patients selected for definitive external beam radiation and a brachytherapy boost were usually medically fit patients with centrally located stage IIIA or IIIB tumours, without weight loss in 6 months leading up to diagnosis. External beam radiation dose ranged from 50-70 Gy with HDR boost of 2.7-10 Gy per fraction at 1-5 fractions over a 1-2 week fraction interval. Response to brachytherapy was assessed by bronchoscopy 1-3 months from completion of treatment. As expected, initial patient performance status, tumour size and stage, and radiation dose are important predictors of outcome [22, 26, 28]. Aygun and colleagues [22] observed that response rates favour patients with tumours not visible radiographically. Higher combined doses of brachytherapy and external beam radiation have been associated with an increased endobronchial response. No complications were seen in patients treated to a dose of $70 \mathrm{~Gy}$, as compared to a $24 \%$ complication rate seen in patients receiving more than $85 \mathrm{~Gy}$ [27]. Common complications are hemoptysis, bronchial stenosis, and bronchitis, with tracheoesophageal fistula being less commonly reported in the literature. Differentiating treatment complications from tumour progression is often challenging as autopsies have been done in only a small proportion of patients undergoing brachytherapy. For tumours in the mainstem or upper lobe bronchus, there appears to be an increased frequency of hemorrhage for right-sided $(25 \%)$ as opposed to left-sided lesions $(25 \%$ and $10 \%$ ), perhaps due to the proximity of the treatment catheter to the pulmonary artery [22].

\section{LDR Brachytherapy}

LDR brachytherapy is another form of radiation therapy with dose rates ranging from $0.1 \mathrm{cGy} / \mathrm{hr}$ to $50 \mathrm{cGy} / \mathrm{hr}$. The radioisotopes most commonly used include Iodine (I-125), Palladium (Pd-103) and gold (Au-198), and when placed inside titanium shells are called seeds. They can be in the form of individual seeds or joined together to form a strand. The overall size of the seed can vary slightly depending on the application.

Hilaris and Martini reviewed the Memorial SloanKettering Cancer Center experience in over 1,000 patients that received intraoperative (LDR) brachytherapy via an open thoracotomy [20]. The use of interstitial brachytherapy as potential curative and palliative treatment of superior sulcus tumours have been reported extensively [29-31]. Results of 129 patient case series have been reported by the Memorial Sloan-Kettering Cancer Center with superior sulcus tumour treated with I-125 for permanent implantation or temporary implantation of Ir-192. The overall survival of this series was encouraging with $25 \%$ survival rate at 5 years favouring patients with adenocarcinomas, negative mediastinal involvement, preoperative radiation therapy followed by surgery. Radiation toxicity includes mild dysphagia for patients who received mild dose of preoperative radiation therapy. Selective intraoperative brachytherapy has been reported by Armstrong et al. [32]. In their case series of 10 patients receiving intraoperative brachytherapy for residual disease, in spite of the advanced disease in the brachytherapy group, actual progression free survival at 2 years and 5 years was $66 \%$ and $55 \%$ respectively. Intraoperative LDR lung brachytherapy alone or in combination with other local and systemic therapies suggest that a subgroup of patients with gross or microscopic disease left in the thorax after incomplete resection or biopsy only, can be controlled locally [33].

Interstitial brachytherapy is not used frequently in clinical practice. This may be due to difficulty in gaining expertise with interstitial techniques, as compared to external beam treatment planning or even endobronchial brachytherapy. Endobronchial brachytherapy is more widely practiced in many cancer centers [10, 34]. Brachytherapyrelated complications have been graded and management has been proposed [25, 35].

Brachytherapy-related hemoptysis has been graded as massive (fatal) or not massive, and management is the same as hemoptysis from other causes. Treatment includes bed rest, codeine, fluid replacement, avoidance of anticoagulants, selective lung insulation and bronchial artery embolization. A brachytherapy related bronchitis grading system to enable comparison of complication between various dosefractionation regimens has been proposed by Speiser and Spratling [25] and management is summarized in Table $\mathbf{2}$.

\section{INTERSTITIAL BRACHYTHERAPY - A CHALLENGING PROCEDURE}

Interstitial brachytherapy allows more precise delivery of radiation and easier adaptation to the tumour shape than is possible with external radiation [20,36], and a higher dose can be delivered to the tumour volume with less damage to the normal lung. The seeds are implanted into cancerous tissue using long and hollow needles, which have small outer diameters and at least one sharp end to allow penetration through the tissue. The seeds are manually loaded into the needle barrel and are spaced from each other by one or more inert spacers that are implanted together with the seeds. A small amount of bone wax is placed on the tip of the implant needles to prevent the seeds from falling out and to prevent the tissue from entering the hollow needle. A stylet inserted in the needle behind the last seed is used to release the bone wax and drop the seeds.

During the brachytherapy procedure, the goal is to implant the seeds into the tumour such that they are uniformly distributed in a particular pattern selected to ensure that the tumour receives the appropriate dose. In general, a series of aligned seeds is introduced with each insertion of the needle. To achieve this goal, each needle must be accurately inserted into the tissue following a particular path and reaching a specified depth. Accurate placement is required to avoid over-radiated and underradiated areas, and to ensure that all the seeds are located 
Table2. Grading of Radiation Bronchitis and Management

\begin{tabular}{|c|c|c|}
\hline Grading & Radiation Bronchitis & Treatment \\
\hline \hline Grade I & $\begin{array}{c}\text { Mild mucosal inflammatory response with swelling, characterized by a thin, whitish, } \\
\text { circumferential membrane. No significant luminal obstruction. }\end{array}$ & Observation \\
\hline Grade II & $\begin{array}{c}\text { White fibrinous membrane with exudation causing systems such as cough and /or obstructive } \\
\text { problems }\end{array}$ & $\begin{array}{c}\text { Steroids-oral and /or aerosol Fluconazole } \\
\text { Saline-diluted bronchodilators } \\
\text { Narcotic cough suppressants }\end{array}$ \\
\hline Grade III & $\begin{array}{c}\text { Severe inflammatory response with marked membranous exudate. Multiple debridement or } \\
\text { other interventions required to reestablish full lumen of airway. }\end{array}$ & $\begin{array}{c}\text { Balloon or bougie dilatation } \\
\text { Laser photoresection } \\
\text { Debridement } \\
\text { Stents }\end{array}$ \\
\hline Grade IV & Greater degree of fibrosis with resulting circumferential stenosis leading to a decrease in \\
luminal diameter. & Same as in Grade III \\
\hline
\end{tabular}

within the target region. Once the needle has accurately reached the target location, the needle barrel is retracted towards the stationary stylet, thereby dropping from the tip of the needle.

This procedure is commonly performed in the prostate, for which coordinate grids are often used to guide the needle insertion in order to improve the accuracy of needle placement, while real-time ultrasound images are used to guide the needles to the desired depth. In a common prostate brachytherapy procedure, $80-100$ seeds are implanted into the prostate using between 20 and 25 needles.

The biggest challenge in delivering radiation therapy is achieving an accurate dosage of radiation. Since the entire treatment is very complex, careful consideration of the planning and delivery is required in order to optimize results and minimize side effects [37]. During a lung brachytherapy procedure, this challenge translates into accurately placing the seeds, since small deviations in seed alignment can create significant areas of over-dosage and under-dosage. Some of the causes for seed misplacement are as follows:

I. Difficulty in accessing the surgical site due to the presence of bone structures (rib cage), major nerves, or blood vessels. Significant clinical expertise is needed to properly access the surgical site [38].

II. Difficulty in locating the needle prior to the penetration, and in achieving the proper penetration depth.

III. During needle barrel retraction, difficulty in holding of the stylet stable relative to the needle. Small unintended movements of the stylet relative to the barrel can result in inaccurate seed placement and a reduction in the effectiveness of the treatment.

IV. Changes in tissue location and size between dose planning and seed implantation [39].

V. Patient movement during the procedure due to tissue shift, breathing, heartbeat, or swelling of the organs.

Furthermore, in traditional brachytherapy procedure the surgical personnel are exposed to the radiation source for a large amount of time. Manual insertion of the needles can take a long time, since it sometimes requires as many as 20 insertions prior to achieving accurate placement.
The use of LDR encapsulated I-125 seeds with its 60 days half-life and low energy photon make interstitial brachytherapy more practical. It greatly reduces the radiation outside of the treatment volume and minimizes the medical and nursing staff exposure. However, the intraoperative radiation exposure to the surgeon and radiation oncologist and the need for a large open thoracotomy with only a modest survival advantage has hindered its clinical acceptance.

There is only limited experience with LDR interstitial brachytherapy under bronchoscopic, fluoroscopic and CT guidance $[2,20,40-42]$. Although the CT-guided percutaneous approach is feasible, it is limited to small and soft tumours in the periphery of the lung, and the optimum radiation dose distribution frequently cannot be achieved due to the bony structures in the chest wall that inhibits precise seed implantation. The risk of injury to proximal mediastinal structures, bleeding, and lung collapse, also limits this technique to only small tumours adjacent to the chest wall.

\section{ROBOTICS-ASSISTED MINIMALLY INVASIVE THORACIC SURGERY}

Minimally invasive surgery (MIS) employs the use of instruments through small incisions in the patient's chest or abdomen to remove cancers. The procedure relies on endoscopic video images for guidance, and the surgeon for instrument manipulation. Procedure-related intraoperative complications can be dealt with immediately. Compared with a thoracotomy, MIS or video-assisted thoracoscopic surgery (VATS) offers patients a shorter length of hospital stay, less pain, and a quicker recovery, without compromising the adequacy of the operation [43, 44]. Thousands of VATS lobectomies have been performed since it was pioneered in 1992, but currently most lobectomies are still performed via a thoracotomy. Although most lobectomies could be performed as VATS, less than $5 \%$ are currently performed this way due to limitations of minimal access, restricted manoeuvrability of instruments, and impaired two-dimensional (2D) visualization. The techniques are difficult to learn and therefore not used as often.

Surgical robots have been shown to improve MIS efficiency by providing superior three-dimensional (3D) 
magnification, enhanced dexterity, and improved precision by tremor filtration and motion scaling [45-48]. To the surgeon, surgical robots also offer improved ergonomics, instrument dexterity during VATS, and the opportunity to operate via telesurgery at a safer distance from the radioactive source [49]. Surgical use of robotics, or computer-assisted surgical systems (CAS), has evolved over the last 10 years for the treatment of chest diseases, however, significant development has really only occurred in the last 3 to 4 years. Moreover, because of this modest experience, robotic thoracic procedures currently take more time than non-robotic cases and, thus, are more expensive. The surgical learning curve appears to be steep, especially for the more complex procedures [50]. As surgeons gain greater experience and the complexity and cost of the equipment are reduced, we should expect to see greater use of CAS in thoracic surgery.

The ZEUS ${ }^{\circledR}$ surgical system was the world's first and only telesurgical robotic platform able to provide surgical care at a distance. It had the potential to interface with surgeons in any part of the world and beyond. It was an ergonomically optimal environment that interfaced with a networked operating room and surgical devices. It was developed and manufactured by Computer Motion, Inc. Computer Motion merged with its competitor, Intuitive Surgical, Inc. and ZEUS robotic platform was replaced by the da Vinci ${ }^{\circledR}$ platform.

The da Vinci Surgical System combines superior 3D visualization along with greatly enhanced dexterity, precision, and control, in an intuitive, ergonomic interface with breakthrough surgical capabilities [46-48, 51]. By enhancing surgical capabilities, the robots reduce trauma to the body, reduce blood loss and need for transfusions, decrease post-operative pain and discomfort, lower the risk of infection, decrease hospital stay, allow for faster recovery and return to normal daily activities, reduce scarring, and improve cosmesis. The robots also allow the surgeon to perform minimally invasive procedures more safely, by allowing immediate access to vital structures and the ability to repair injuries that may occur during the brachytherapy procedure.

\section{ADJUVANT BRACHYTHERAPY FOR LUNG CANCER}

The recent increase in MIS has also renewed an interest in the role of adjuvant brachytherapy for lung cancer [5259]. Following resection of small lung tumours (T1N0), intraoperative I-125 seeds have been implanted with Vicryl ${ }^{B}$ mesh along the resection margins $[52,53,57]$. The technique appears to be safe and appears to reduce local tumour recurrence rates, but long-term results are required. Pisch et $a l$. have reported on the ability of da Vinci system to suture in brachytherapy seeds into a porcine lung [56]. MIS wedge resections were performed in the upper and lower lobes. Dummy I-125 seeds embedded in absorbable sutures were sewn into the resection margin with the aid of the da Vinci system without complications. The robotic technology allowed direct placement of radioactive seeds into the resection margin by endoscopic surgery. This renewed enthusiasm for lung brachytherapy has resulted in a multiinstitutional randomized phase III study of sublobar resection versus sublobar resection plus brachytherapy in high-risk patients with nonsmall cell lung cancer sponsored by the American College of Surgeons Oncology Group (ACOSOG 4032) [60]. This study is now closed accrual and results are pending.

It is believed that earlier detection of lung cancer should translate into more effective treatment. Lung cancer screening has been revived with various reports showing an advantage of low-dose CT over chest radiographs in detecting smaller size tumours and at an earlier stage [61]. Studies have found that eighty percent of all the tumours found were of stage I, with an estimated 8-year cure rate for resected lung cancers of $95 \%[62,63]$. This suggests that a higher proportion of deaths from lung cancer can be prevented by CT screening followed by early resection [63, 63]. The gold standard therapy for NSCLC is a lobectomy, while lesser resections are reserved as a compromise operation for high-risk patients $[64,65]$. Earlier studies have suggested that sublobar resections for stage I tumours are complicated by increased locoregional recurrence rates [64, 66]. The increased identification of small NSCLC tumors by CT scan is leading many surgeons to question the appropriateness of lobectomy for these tumors. There is an increasing interest by many surgeons to use sublobar resection as the new standard for patients with small peripheral lung cancers [67]. Intentional sublobar resection for small lung cancers (T1N0) has been performed using minimally invasive techniques with equivalent results [6874]. Recently, intraoperative brachytherapy on the resection staple line has been shown to significantly decrease the local recurrence rates associated with these limited resections [52, $54,55,57,59]$. Our experience with intraoperative brachytherapy reveals this technique can achieve considerable lung volume sparing for irradiation to normal tissue with less than $2 \%$ lung volume receiving $20 \mathrm{~Gy}^{1}$ (Fig. 1). Future directions in the management of early lung cancer will include MIS surgery combined with brachytherapy.

\section{ROBOTICS-ASSISTED MINIMALLY INVASIVE BRACHYTHERAPY FOR LUNG CANCER}

The future of lung cancer therapy may include the placement of individual brachytherapy seeds minimally invasively into lung cancers using a robotics-assisted brachytherapy seed delivery system. The prerequisites for such an approach are: i) a method to localize the tumour intraoperatively; ii) a means of tracking and guiding the needle in real time; iii) 3D images of the tumour from which the dosimetry will be planned (based on the tumour contours); and iv) a brachytherapy seed delivery device for the robot. Here we shall discuss the prerequisites of the robotics-assisted brachytherapy approach.

\section{Lung Tumour Localization}

For minimally invasive brachytherapy to be performed in the lung, it is imperative that some form of image guidance be incorporated for instrument tracking and tumour localization. Tumours that are deep within the lung cannot be seen with the thoracoscope. The procedure is performed

\footnotetext{
${ }^{1} \mathrm{Yu}$ E, Lewis C, Malthaner RA. Intra-operative brachytherapy of localized Non-small cell Lung Cancer. Unpublished data.
} 


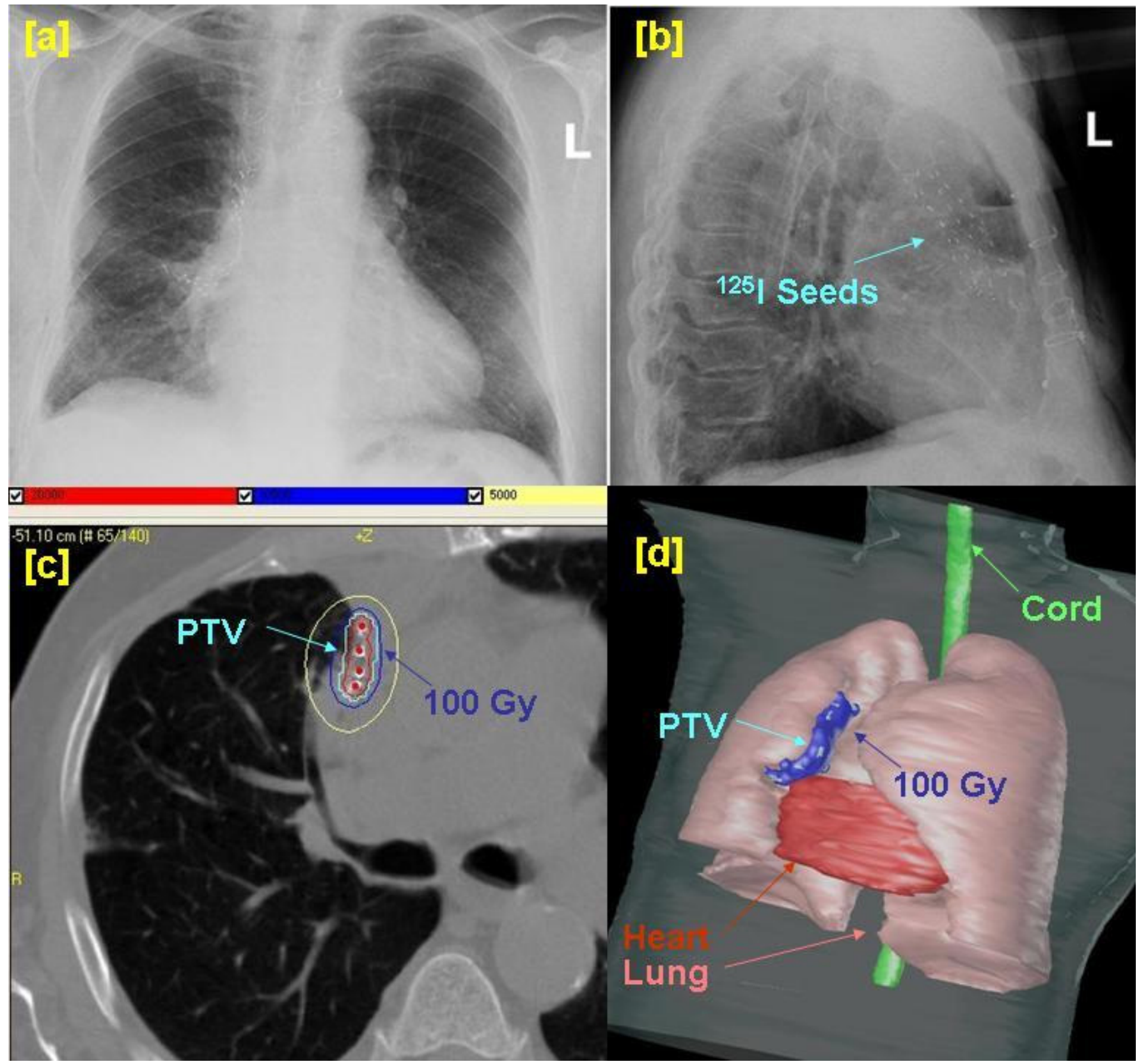

Fig. (1). Intraoperative lung brachytherapy. (A and B) Chest X-ray (PA and lateral films) of a stage I NSCLC patient with limited pulmonary capacity post sublobar resection and intraoperative brachytherapy. (C) Post intraoperative brachytherapy CT -simulation and treatment reveals I-125 seeds in place. Total dose prescribed was $100 \mathrm{~Gy}$ (blue isodose line). Isodose lines are also displayed for $50 \mathrm{~Gy}$ (yellow) and 200 Gy (red). (D) 3D display of the Planning Target Volume (PTV) demonstrating dose coverage by the 100 Gy prescription.

through small incisions making it impossible to palpate the nodules manually [75]. Current tumour localization techniques include methylene blue staining and the insertion of a hook wire [76-81]. These methods have been found to be cumbersome, have a high failure rate, and increase medical risks and litigation [82-84]. A method that can reliably localize lung nodules intraoperatively during a minimally invasive procedure is needed. Although lung tumours may be readily seen using CT imaging, CT scanners are not available in operating rooms for intraoperative use and there is often a delay of several months between a preoperative $\mathrm{CT}$ scan and the actual surgical procedure. From a global perspective, intraoperative ultrasound imaging appears to be the modality of choice. Ultrasound does not expose the patient to radiation as a CT does, and it can achieve real-time dependable dose plans for the delivery of brachytherapy. MIS ultrasound probes are now available from many manufacturers, enabling its use in guiding minimally invasive thoracic surgeries.

\section{Needle Tracking and Guidance}

Much effort has been put into overlaying real-time navigation information into preoperative information to serve as image guidance during procedures. A tracking device can be attached to the tool and its position displayed on the preoperative image (e.g. MRI, PET, CT). Kevin Cleary's group at Georgetown University has developed a 
system for surgical assistance incorporating magnetic tracking and CT image overlay for targeting internal organs such as the liver [85]. Roeddiger's group in Germany [86] has studied virtual reality image overlays for brachytherapy. Their work uses preoperatively acquired image data that is then displayed together with the position of the tracked instrument on a transparent overlay that can be put on top of the patient. An ongoing challenge with the static preoperative CT images is the reduced navigational accuracy due to respiratory motion. Strides have been made with electromagnetic tracking for abdominal interventions [8791]. However, no system exists today that can compensate for lung motion around lung tumours.

Recent advances in electromagnetic tracking systems have led to the miniaturization of the sensors and better immunity to nearby metallic objects. For example, the microBIRD $^{\mathrm{TM}}$ tracking system (Ascension Technology Corporation) features a 6 degree-of-freedom DC magnetic tracker with a sensor diameter of just $1.3 \mathrm{~mm}$. An electromagnetic transmitter situated outside of the body generates a weak spatially varying magnetic field that can be measured by the sensor to dynamically compute position and orientation. Field distortions caused by nearby conductive metals, which significantly affected earlier AC systems, have been minimized using DC pulses.

\section{Brachytherapy Treatment Planning}

CT simulation has been the standard for treatment planning in many modern radiation therapy centres; however, CT simulation is not readily available intraoperatively in most countries. The literature on $3 \mathrm{D}$ ultrasound simulation with permanent brachytherapy seed implantation treatment planning in lung cancer is limited [92]. The number of permanent seeds used in a given tumour volume and the angle of brachytherapy needle entry for a given tumour mass have yet to be defined. The dosimetry plan for MIS interstitial brachytherapy seeds in lung tumours is unknown. Standard needle templates used in prostate brachytherapy are not usable for intrathoracic tumours due to the bony rib cage and the restriction of only one entry port as a component of MIS. New approaches need to be developed.

\section{Brachytherapy Seed Delivery System}

Many researchers have been working on ways to improve brachytherapy procedures. Currently the most common usage of brachytherapy is in the treatment of prostate cancer and hence many of the developments have focused on this area. The contributions found in the literature can be summarized as follows: control of the relative motion between the hollow needle and the plunger [93]; accurate positioning and orienting of the needle prior to penetration [94-96]; drivers for needle penetration [37, 96, 97]; real-time image guidance during needle insertion [85, 94-98]; force feedback during needle insertion [96-99]; and tissue motion compensation [100-103]. However, none of these devices is currently available on the market due to their complexity and lack of regulatory approval for clinical use. Additionally, they are designed only for percutaneous needle insertion, and most have been designed specifically to treat tumours located in the prostate. The process of implanting seeds within lung cancerous tissue could greatly benefit from the use of minimally invasive robotic systems; however, an instrument that can be attached to these systems for brachytherapy is not currently available.

We shall describe some of the pioneer work at Canadian Surgical Technologies and Advanced Robotics (CSTAR) on Robotics-Assisted Brachytherapy for the potential future management of lung cancer.

\section{SYSTEM AT CSTAR}

Our work at CSTAR has focused on six areas: i) development of a lung tumour model and robotic brachytherapy test bed; ii) development of 3D ultrasound imaging for lung tumours; iii) design of a delivery system for robotic brachytherapy; iv) robotics-assisted brachytherapy using the ZEUS platform; v) development of an electromagnetic navigation system for precise needle insertion; and vi) dosimetry planning.

An experimental test bed was developed to assess the feasibility of robotics-assisted minimally invasive lung brachytherapy when compared to other more traditional methods [104-106] (Fig. 2). The system consists of a Video Assisted Thoracic Surgery (VATS) box, surgical robotic arms, a customized seed injector, an ultrasound machine, an electromagnetic tracking system, video monitors, a computer, and an endoscope. The ZEUS surgical system consists of two arms for instruments. The endoscopic camera is held by the AESOP robotic endoscope holder. All three arms can be teleoperated by the surgeon from a computerbased remote console. The instrument arms mimic the motion of hand-held instruments, which are manipulated by the surgeon from the remote console. Control systems were designed for the ZEUS arms that replaced the existing controllers in order to provide more accurate and versatile control of the motions of the two arms. One of the arms can be used to hold and manipulate the ultrasound probe, and another to hold and position the seed injector [107].

In this setup, the Aurora electromagnetic tracking system (Northern Digital Inc.) was used to track the location of the needle and the ultrasound probe. The tiny sensors available as part of the Aurora system allowed the placement of the sensor at the tip of the stylet inside the needle [106].

In order to use the robotic system to deposit radioactive seeds inside a lung tumour within a minimally invasive environment when the target tumour is located within the lung and thus is not visible, we developed the InterNav3.0 ${ }^{\mathrm{TM}}$ software environment [108]. It incorporates the ultrasound image, the information from the electromagnetic sensors, and calibration data to provide the user with enough information to accurately guide and position a needle at a desired target. A Graphical User Interface (GUI) was developed as a front end for the InterNav3.0 application. The InterNav3.0 GUI consists of several views that provide a wealth of information and functionality. Not only does the GUI allow the user to visualize the anatomical area of interest, it also allows the user to select the appropriate target, and provide all of the information required to guide the needle towards the target in a quick and intuitive manner (Fig. 3). 


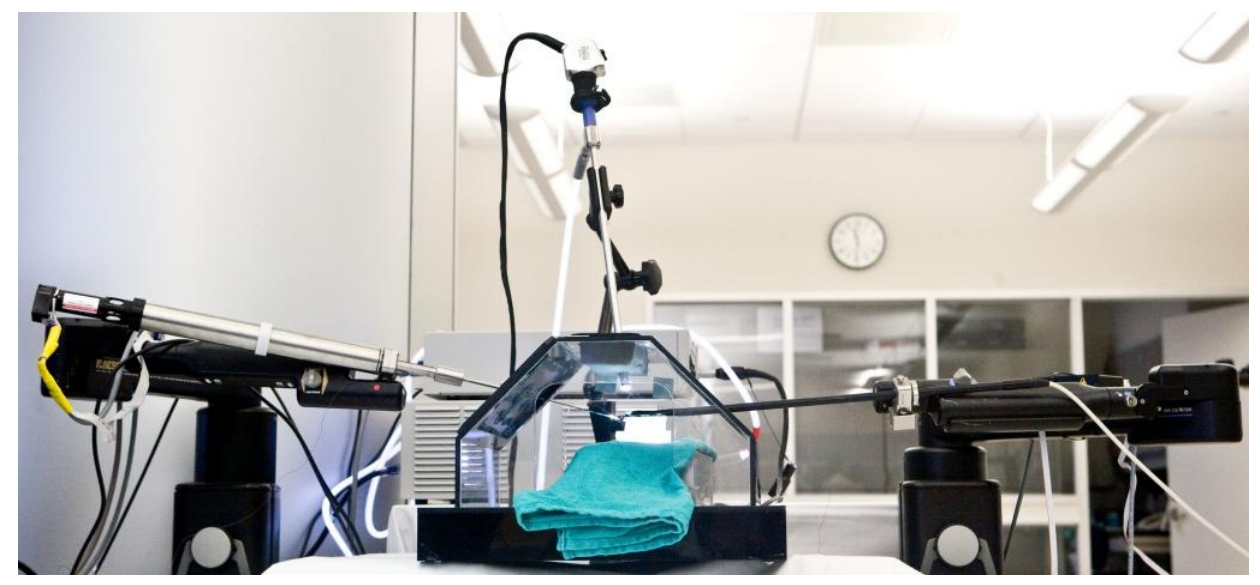

Fig. (2). MIRA V System showing the three robotic arms holding the seed injector, the thoracoscope, and the MIS ultrasound probe. (Photo credit: Meg Woodhouse).

The robotic arm carrying the seed injector allows the position and orientation of the needle to be adjusted inside the patient's body prior to penetrating the target tissue. The MIS approach allows better access to organs inside the thoracic cavity, and therefore can safely avoid vital structures. The injector can easily penetrate the more scirrhous tumours, and the remote actuation of the needle retraction system reduces the exposure of the clinician to the radiation source.

A technique for creating intraoperative, near real time, 3D ultrasound images of human lung nodules using MIS techniques was developed [109]. Multiple 2D ultrasound images of a subpleural nodule scanned intraoperatively were reconstructed into 3D images. We adapted the HDI 5000 LapL9-5 laparoscopic probe to a transducer holder containing a mechanical motor attached to a standard computer. The modified probe was used to thoracoscopically detect and remove a subpleural nodule through three $12 \mathrm{~mm}$ incisions. The device was easy to use and the images accurately identified the tumour. The images correlated well with the preoperative CT scan and final pathology. Intraoperative 3D ultrasound proved to be feasible in localizing invisible or nonpalpable lung nodules in near real time and provided an accurate representation of the anatomy during thoracoscopic lung surgery. This is the world's first example of thoracoscopic 3D ultrasound imaging of a human lung nodule (Fig. 4) [109].

An ex vivo lung tumour model, using excised porcine lung and agar tumours was developed to provide a means of verifying $3 \mathrm{D}$ ultrasound images and to provide a teaching tool for intraoperative lung ultrasound techniques $[110,111]$. Spherical tumours of various size were made from agar and were inserted through incisions on the underside of an excised porcine lung. The average coefficient of variation and volume error during tumour localization was $11.2 \%$ and $12.9 \%$ respectively, and tumour volume error decreased as the tumour size increased $[111,112]$.

Our initial proof of principle experiments demonstrated that permanent interstitial brachytherapy seeds can be safely and reproducibly inserted using an MIS technique with the assistance of the ZEUS robotic system and intraoperative ultrasound into in vivo porcine lungs [113]. There were no problems with bleeding or air leaks. The ZEUS system performed well and was able to remotely manipulate the ultrasound transducer and needle to allow deployment of the seeds [114]. The ultrasound images were of good quality, and provided adequate visualization of the needle insertion and seed deployment. There was no evidence of seed embolization in the two animals during three months. These experiments showed that interstitial brachytherapy seeds can be safely inserted into lungs using the ZEUS robotic system with $2 \mathrm{D}$ ultrasound image guidance.

We also compared the accuracy, effort, and time needed to place seeds next to a target using a manual method (open surgery), video-assisted thoracoscopy (VATS), and the ZEUS robot $[115,116]$. Our brachytherapy seed injector was mounted on the ZEUS system [107]. Four different people inserted dummy brachytherapy seeds into clear agar-gelatin cubes containing a $1.6 \mathrm{~mm}$ stainless steel ball serving as a visible target. As anticipated, the open surgery technique with manual needle insertion is the most accurate, least traumatic (requiring less needle punctures), and the fastest method of inserting seeds into tumours. However, the ZEUS robotics-assisted brachytherapy was less traumatic and faster than the VATS technique.

Further experimental results showed that the InterNav3.0 electromagnetic navigation system improved the performance of minimally invasive brachytherapy procedures in terms of effort and median tissue trauma, while also showing promise in improving the accuracy of seed deployment ${ }^{2}$. With manual insertions, the navigation system offered no advantage in time, although it led to a reduction of the number of attempts and an improvement in accuracy. The benefit of a guidance system was manifested only when visual information becomes limited in MIS scenarios; whereas the intuitive three-dimensional spatial perception afforded by the open manual technique has made an add-on guiding system seem unnecessary. When procedures must be done minimally invasively, however, electromagnetic guidance becomes essential. The addition of image guidance reduced the average task completion time of

${ }^{2}$ Pytel M, Trejos AL, Patel RV, and Malthaner RA. The InterNav electromagnetic guidance system for robotic needle insertion. 2006/1/10. Unpublished data. 


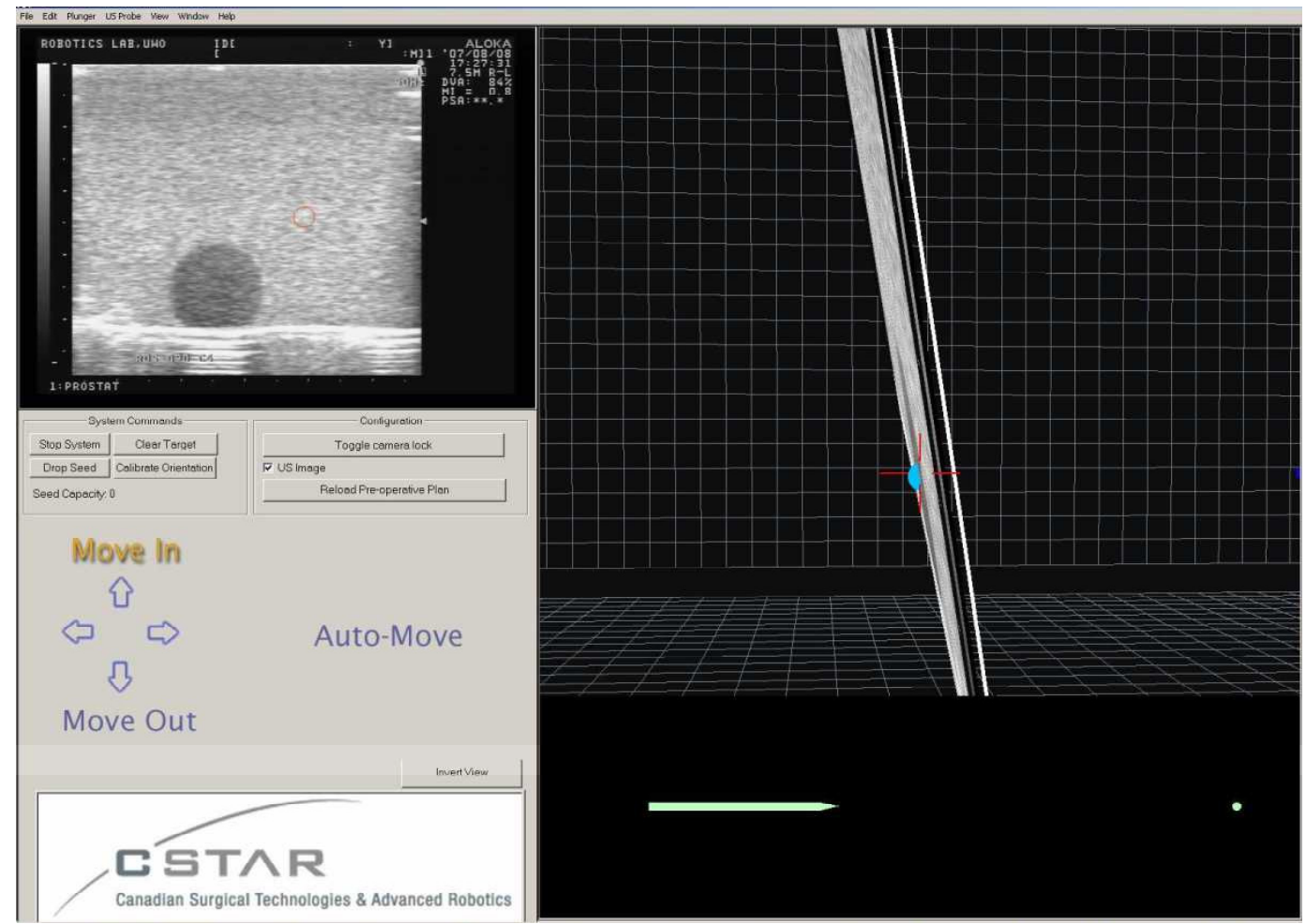

Fig. (3). InterNav3 $30^{\mathrm{TM}}$ user interface showing the Ultrasound View (top left), the position of the target (blue sphere) with respect to the needle tip in the World View (top right), and the depth of the needle tip with respect to the target in the Depth View (bottom right). The controls for moving the seed injector and dropping the seeds are also part of the user interface (bottom left).

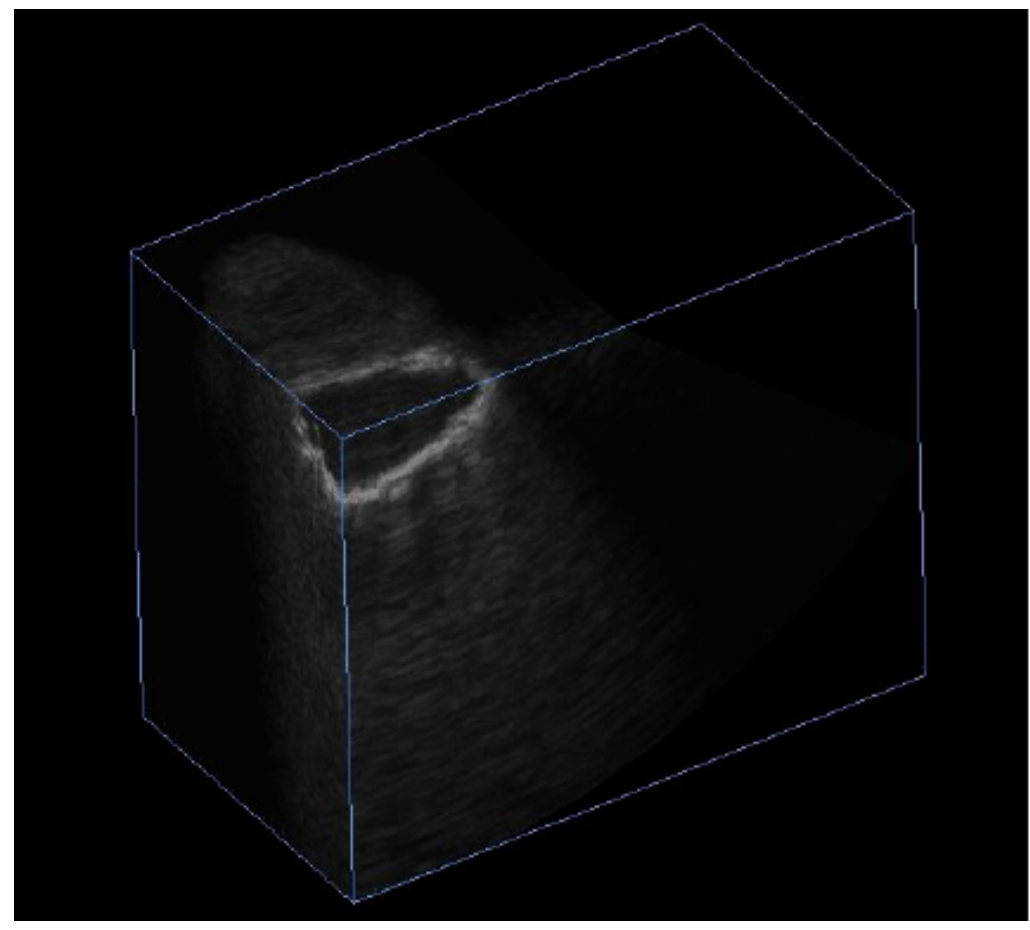

Fig. (4). 3D ultrasound image of a human lung tumour.

one seed insertion by 60 seconds. For the robotic procedure, the average time was reduced by 30 seconds. The time saved becomes even more significant when more seeds need to be inserted.
Dosimetry planning was assessed using the Theraplan Plus ${ }^{\circledR}$ software and has been found feasible [93]. In an effort to realize real time dosimetry replanning as brachytherapy seeds are deposited, preliminary software was developed by Dr. A. Fenster's research team. The software accounts for actual seed position and recalculates the dosimetry as more 


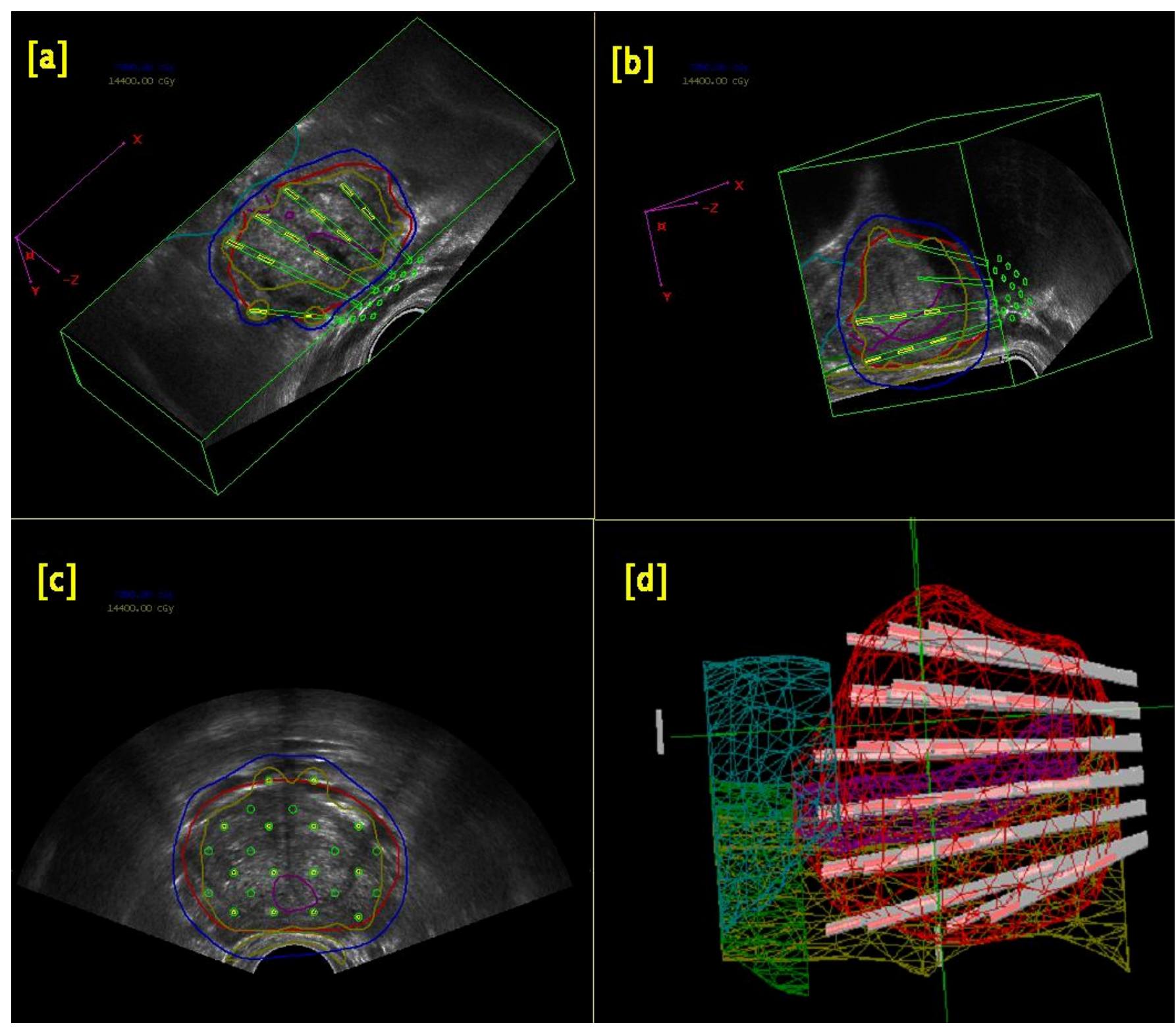

Fig. (5). Image of a dosimetry plan for brachytherapy using 3D ultrasound imaging. (Courtesy of Dr. Aaron Fenster).

seeds are deposited (Fig. 5). The software has been modified from a template based system for prostate implants to allow nonparallel needle insertion that would be necessary in a minimally invasive approach. In vitro and ex vivo experiments were done to test the performance of the system in terms of its ability to optimize the quality of the radiation coverage on phantom tumours.

Three-dimensional ultrasound scans of phantom agar tumours were used for preplanning seed locations. The in vitro PTVs covered by at least $100 \%$ the prescribed dose (V100) was about 97\%; that covered by at least $90 \%$ of the prescribed dose (V90) was about 99\%. The minimum dose received by $90 \%$ of the volume (D90), a parameter that is most sensitive to deviations in seed deposition, remained high at about 125 Gy (compared to preplan value of about 145 Gy). The results using ex vivo porcine lungs were slightly less accurate, although still acceptable in terms of potential for future therapeutic use. The lung brachytherapy system performed well in both in vitro and on ex vivo lung tissue ${ }^{3}$.

\section{LIMITATIONS AND FUTURE DIRECTIONS}

A major limitation to any electromagnetic tracking system is the possible distortion in the field by magnetic interference caused by the presence of nearby metal objects. Improvements in technology have made the current generation of sensors less susceptible to such interferences. Our experience was that modest amounts of surgical steel in the environment do not cause any noticeable deterioration of accuracy. However, it would still be important to keep the amount of metal to a minimum, and the addition of metallic shields could ensure optimal performance.

\footnotetext{
${ }^{3}$ Lin AW, Trejos AL, Bhatia P, et al. Minimally Invasive Robot-Assisted Image-Guided Optimal Dosimetry Planning And Execution Model For Lung Brachytherapy. Unpublished data.
} 
The accuracy of brachytherapy seed injection was limited by the intrinsic resolution of the ultrasound probe. This resolution may be somewhat improved by using a newer probe or one with higher frequency (although this would have been at the expense of penetration depth). 3D ultrasound may hold the key to improved visualization and real time dosimetry planning. A better sense of the tissue may be obtained through reconstruction of the $3 \mathrm{D}$ space by piecing together $2 \mathrm{D}$ images and their position information.

\section{CONCLUSION}

Lung cancer brachytherapy has been advocated for years. Recent advances in technology such as robotic assistance and image guidance give promise to improved performance of minimally invasive lung brachytherapy procedures, potentially expanding its clinical role and facilitating better patient outcomes. Robotic assistance enables precise manipulation of the brachytherapy needle while enhancing the ergonomics for the surgeon and radiation oncologist; real-time virtual reconstruction of the tissue of interest and image guidance allows more intuitive and reliable seed deposition. By integrating these two aspects of technology, the surgical procedure can be made more automatic, easier to learn, less susceptible to user variability, and may translate into better treatment efficacy with fewer side effects.

\section{ACKNOWLEDGEMENT}

The authors wish to thank A.W. Lin, M. Pytel, H. Bassan, and S. Mohan for their research contributions to the lung brachytherapy project.

\section{DISCLOSURE}

Part of the information included in this review has been previously published in TELESURGERY 2008, 33-52.

\section{CONFLICT OF INTEREST}

The authors have no conflicts of interest to report.

\section{ABBREVIATIONS}

$$
\begin{aligned}
& \text { 2D }=\text { Two-dimensional } \\
& 3 \mathrm{D}=\text { Three-dimensional } \\
& \mathrm{AC}=\text { Alternating current } \\
& \text { CAS }=\text { Computer-assisted surgical systems } \\
& \text { Robotics } \\
& \mathrm{CT}=\text { Computed tomography } \\
& \mathrm{DC}=\text { Direct current } \\
& \text { GUI = Graphical User Interface } \\
& \text { HDR }=\text { High dose rate } \\
& \text { LDR }=\text { Low dose rate } \\
& \text { MRI = Magnetic resonance imaging } \\
& \text { MIS = Minimally invasive surgery } \\
& \text { NSCLC }=\text { Non small cell lung cancer }
\end{aligned}
$$$$
\text { CSTAR }=\text { Canadian Surgical Technologies \& Advanced }
$$

PET = Positron emission tomography

US $=$ Ultrasound

VATS $=$ Video-assisted thoracic surgery

\section{REFERENCES}

[1] CBC News. Cancer passes heart disease as top killer in U.S. Cancer Care Ontario Practice Guidelines Available from: http://news.bbc.co.uk/2/hi/health/4267513.stm [Accessed 2010, August 25]

[2] Martinez-Monge R, Garran C, Vivas I, Lopez-Picazo JM. Percutaneous CT-guided 103Pd implantation for the medically inoperable patient with T1N0M0 non-small cell lung cancer: a case report. Brachytherapy 2004; 3(3):179-81.

[3] Aye RW, Mate TP, Anderson HN, et al. Extending the limits of lung cancer resection. Am J Surg 1993; 165: 572-6.

[4] Ginsberg RJ, Martini N, Zaman N, et al. Influence of surgical resection and brachytherapy in the management of superior sulcus tumour. Ann Thorac Surg 1994; 57: 1440-5.

[5] Nori D, Baines M, Hilaris BS, et al. New intraoperative brachytherapy techniques for positive or close surgical margins. J Surg Oncol 1989; 42: 54-9.

[6] Hilaris BS, Nori D, Beattie EJ, et al. Value of perioperative brachytherapy in the management of non-oat cell carcinoma of the lung. Int J Radiat Oncol Biol Phys 1983; 9: 1161-6.

[7] Mittal BB, Nemcek AA Jr, Sider L. Malignant tumors invading chest wall: Treatment with CT-directed implantation of radioactive seeds. Radiology 1993; 186: 901-3.

[8] Hall EJ. Radiobiology for the radiologist. $5^{\text {th }}$ ed. Philadelphia: Lippincott Williams \&Wilkins 2000.

[9] Nag S, Kelly JF, Horton JL, et al. Brachytherapy for carcinoma of the lung. Recommendations from the American Brachytherapy Society. Oncology (Hunting) 2001; 15: 371-81.

[10] Ung YC, Yu E, Falkson C, et al. The role of high-dose-rate brachytherapy in the palliation of symptoms in patients with nonsmall-cell lung cancer: a systematic review. Brachytherapy 2006; 5(3): 189-202.

[11] Langendijk H, deJong J, Tjwa M, et al. External irradiation versus external irradiation plus endobronchial brachytherapy in inoperable non-small cell lung cancer: a prospective randomized study. Radiother Oncol 2001; 58: 257-68.

[12] Sur R, Ahmed SN, Donde B, et al. Brachytherapy boost vs teletherapy boost in palliation of symptomatic locally advanced non small cell lung cancer. Preliminary analysis of a randomized, prospective study. J Brachyther Int 2001; 17: 309-15.

[13] Sur R, Donde B, Mohuiddin M, et al. Randomized prospective study in palliation of symptoms in advanced non small cell lung cancer treated with radiation alone. Int J Radiat Oncol Bio Phys 2004; 60: abstr 127.

[14] Stout R, Barber P, Burt P, et al. Clinical and quality of life outcomes in the first United Kingdom randomized trial of endobronchial brachytherapy (intraluminal radiotherapy) $v s$ external beam radiotherapy in the palliative treatment of inoperative non small cell lung cancer. Radiother Oncol 2000; 56: 323-7.

[15] Harms W, Krempien R, Grehn C, Hensley F, Debus J, Becker HD. Electromagnetically navigated brachytherapy as a new treatment option for peripheral pulmonary tumors. Strahlentherapie und Onkologie 2006; 182(2): 108-11.

[16] Brach B, Buhler C, Hayman MH, Joyner LR Jr, Liprie SF. Percutaneous computed tomography-guided fine needle brachytherapy of pulmonary malignancies. Chest 1994; 106(1): 268-74.

[17] Imamura F, Chatani M, Nakayama T, Uda H, Nakamura S, Horai T. Percutaneous brachytherapy for small-sized non-small cell lung cancer. Lung Cancer 1999; 24(3): 169-74.

[18] Ricke J, Wust P, Hengst S, Wieners G, Pech M, Herzog H, Felix R. CT-guided interstitial brachytherapy of lung malignancies. Technique and first results. Radiologe 2004; 44(7): 684-6.

[19] Ricke J, Wust P, Wieners G, Hengst S, Pech M, Lopez Hanninen E, Felix R. CT-guided interstitial single-fraction brachytherapy of lung tumors: phase I results of a novel technique. Chest. 2005; 127(6): $2237-42$. 
[20] Hilaris BS, Martini N. The current state of intraoperative interstitial brachytherapy in lung cancer. International Journal of Radiation Oncology, Biology, Physics 1988; 15(6): 1347-54.

[21] Kohek PH, Pakisch B, Glanzer H. Intraluminal irradiation in the treatment of malignant airway obstruction. Eur J Surg Oncol 1994; 20: $674-80$.

[22] Aygun C, Weiner S, Scariato A, et al. Treatment of non-small cell lung cancer with external beam radiotherapy and high dose rate brachytherapy. Int J Radiat Oncol Biol Phys 1992; 23: 127-32.

[23] Change LL, Horvath J, Peyton W, et al. High dose rate afterloading intraluminal brachytherapy in malignant airway obstruction of lung cancer. Int J Radiat Oncol Biol Phys 1994; 28: 589-96.

[24] Speiser BL, Spratling L. Remote after loading brachytherapy for the local control of endobronchial carcinoma. Int J Radiat Oncol Biol Phys 1993; 25: 579-87.

[25] Speiser BL, and Spratling L. Radiation bronchitis and the stenosis secondary to high dose rate endobronchial irradiation. Int J Radiat Oncol Biol Phys 1993; 25: 589-97.

[26] Zajac AJ, Kahn ML, Heiser D, et al. High dose rate intraluminal brachytherapy in the treatment of endobronchial malignancy. Work in progress. Radiology 1993; 187: 571-5.

[27] Cotter GW, Laricy C, Ellingwood KE, et al. Inoperable endobronchial obstructing lung cancer treated with combined endobronchial and external beam irradiation: a dosimetric analysis. Int J Radiat Oncol Biol Phys 1993; 27: 531-5.

[28] Huber RM, Fischer R, Hautmann H, et al. Palliative endobronchial brachytherapy for central tumours. A prospective, randomized comparison of two fraction schedules. Chest 1995; 107: 463-70.

[29] Hilaris BS, Luomanen RK, Mahan BS, et al. Interstitial irradiation of apical lung cancer. Radiology 1971; 99: 655-60.

[30] Hilaris BS, Martini N, Luomanen JK, et al. The value of preoperative radiation therapy in apical cancer of the lung. Surg Clin N Am 1974; 54: 831-40.

[31] Hilaris BS, Martini N, Wong GU, et al. Treatment of superior sulcus tumours (Panccoast tumor). Surg Clin N Am 1987; 65: 96577.

[32] Armstrong JG, Martini N, Kris MG, et al. Induction chemotherapy for non-small cell lung cancer with clinically evident mediastinal node metastases: the role of postoperative radiotherapy. Int J Radiat Oncol Biol Phys 1992; 23: 605-13.

[33] Hilaris BS, and Mastoras DA. Contemporary brachytherapy approaches in non-small cell lung cancer J Surg Oncol 1998; 69: $258-64$.

[34] Nag S, Owen JB, Farnan N, et al. Survey of brachytherapy practice in the United States: A report of the Clinical Research Committee of the American Endocurietherapy Society. Int J Radiat Oncol Biol Phys 1995; 31: 103-7.

[35] Gasper LE. Brachytherapy in lung cancer. J Surg Oncol 1998; 67: 60-70.

[36] Fleischman EH, Kagan AR, Streeter OE, et al. Iodine125 interstitial brachytherapy in the treatment of carcinoma of the lung. J Surg Oncol 1992; 49(1): 25-8.

[37] Ng WS, et al. Robotic radiation seed implantation for prostatic cancer. Proceedings of the 18th Annual International Conference of the IEEE, Engineering in Medicine and Biology Society: Bridging Disciplines for Biomedicine 1996 Oct 31-Nov 3; 1: 231-3.

[38] Stoianovici D, Cadeddu JA, Demaree RD, et al. A novel mechanical transmission applied to percutaneous renal access. Proceedings of ASME Dynamic Systems and Control Division 1997; DSC-61: 401-6

[39] Nag S, Kelly JF, Horton JL, Komaki R, and Nori D. Brachytherapy for carcinoma of the lung. Oncology (Williston.Park) 2001; 15(3): 371-81.

[40] Sider L, Mittal BB, Nemcek AA Jr, Bobba VS. CT-guided placement of iodine- 125 seeds for unresectable carcinoma of the lung. J Comput Assist Tomogr 1988; 12(3): 515-7.

[41] Tomberlin JK, Halperin EC, Kusin P, et al. Endobronchial interstitial Au-198 implantation in the treatment of recurrent bronchogenic carcinoma. J Surg Oncol 1992; 49(4): 213-9.

[42] Mittal BB, Nemcek AA Jr, and Sider L. Malignant tumors invading chest wall: treatment with CT-directed implantation of radioactive seeds. Radiology 1993; 186(3): 901-3.

[43] McKenna RJ Jr, Houck W, and Fuller CB. Video-assisted thoracic surgery lobectomy: experience with 1,100 cases. Ann Thorac Surg 2006; 81(2): 421-5.
[44] McKenna RJ Jr. The current status of video-assisted thoracic surgery lobectomy. Chest Surg Clin of North America 1998; 8(4): 775-85.

[45] Buckingham RA, Buckingham RO. Robots in operating theatres. BMJ 1995; 311(7018): 1479-82.

[46] Panait L, Doarn CR, Merrell RC. Applications of robotics in surgery. Chirurgia (Bucur.) 2002; 97(6): 549-55.

[47] Munz Y, Moorthy K, Dosis A, Hernandez, et al. The benefits of stereoscopic vision in robotic-assisted performance on bench models. Surg Endosc 2004; 18(4): 611-6.

[48] Corcione F, Esposito C, Cuccurullo D, et al. Advantages and limits of robot-assisted laparoscopic surgery: preliminary experience. Surg Endosc 2005; 19(1): 117-9.

[49] Morgan JA, Ginsburg ME, Sonett JR, Argenziano M. Thoracoscopic lobectomy using robotic technology. Heart Surg Forum 2003; 6(6): E167-E169.

[50] Kernstine KH. Robotics in thoracic surgery. American Journal of Surgery 2004; 188(4A Suppl): 89S-97S.

[51] Intuitive Surgical Inc. da Vinci Robot. Available from: http://www.intuitivesurgical.com/products/ [Accessed 2010, August 25].

[52] d'Amato TA, Galloway M, Szydlowski G, Chen A, Landreneau RJ. Intraoperative brachytherapy following thoracoscopic wedge resection of stage I lung cancer. Chest 1998; 114(4): 1112-5.

[53] Chen A, Galloway M, Landreneau R, et al. Intraoperative 125I brachytherapy for high-risk stage I non-small cell lung carcinoma. Int J Radia Oncol, Biol, Phys 1999; 44(5): 1057-63.

[54] Lee W, Daly BD, DiPetrillo TA, et al. Limited resection for nonsmall cell lung cancer: observed local control with implantation of I-125 brachytherapy seeds. Ann Thorac Surg 2003; 75(1): 237-242.

[55] Santos R, Colonias A, Parda D, et al. Comparison between sublobar resection and 125Iodine brachytherapy after sublobar resection in high-risk patients with Stage I non-small-cell lung cancer. Surgery 2003; 134(4): 691-7.

[56] Pisch J, Belsley SJ, Ashton R, Wang L, Woode R, Connery C. Placement of 125I implants with the da Vinci robotic system after video-assisted thoracoscopic wedge resection: a feasibility study. Int J Radia Oncol, Biol, Phys 2004; 60(3): 928-32.

[57] Fernando HC, Santos RS, Benfield JR, et al. Lobar and sublobar resection with and without brachytherapy for small stage IA nonsmall cell lung cancer. J Thorac Cardiovasc Surg 2005; 129(2): 261-7.

[58] Voynov G, Heron DE, Lin CJ, et al. Intraoperative (125)I Vicryl mesh brachytherapy after sublobar resection for high-risk stage I non-small cell lung cancer. Brachytherapy 2005; 4(4): 278-85.

[59] Birdas TJ, Koehler RP, Colonias A, et al. Sublobar resection with brachytherapy versus lobectomy for stage $\mathrm{Ib}$ nonsmall cell lung cancer. Ann Thorac Surg 2006; 81(2): 434-8.

[60] American College of Surgeons Oncology Group. Z4032 Study: A Randomized Phase III Study of Sublobar Resection versus Sublobar Resection plus Brachytherapy in High Risk Patients with Non-Small Cell Lung Cancer (NSCLC), $3 \mathrm{~cm}$ or smaller. Available from: http://clinicaltrials.gov/ct2/show/NCT00107172 [Accessed 2010, Aug 25].

[61] Artinian V, Kvale PA. Update in screening of lung cancer Respirology. 2005; 10(5): 558-66.

[62] Henschke CI. CT screening for lung cancer: update 2005. Surg Oncol Clin N Am 2005; 14(4): 761-76.

[63] Henschke CI, Shaham D, Yankelevitz DF, Altorki NK. CT screening for lung cancer: past and ongoing studies. Semin Thorac Cardiovasc Surg 2005; 17(2): 99-106.

[64] Ginsberg RJ, Rubinstein LV. Randomized trial of lobectomy versus limited resection for T1 N0 non-small cell lung cancer. Lung Cancer Study Group. Ann Thorac Surg 1995; 60(3): 615-22.

[65] Smythe WR. Treatment of stage I non-small cell lung carcinoma. Chest 2003; 123(1 Suppl): 181S-187S.

[66] Landreneau RJ, Sugarbaker DJ, Mack MJ, et al. Wedge resection versus lobectomy for stage I (T1 N0 M0) non-small-cell lung cancer. J Thorac Cardiovasc Surg 1997; 113(4): 691-8.

[67] Ketchedjian A, Daly B, Landreneau R, aFernando H. Sublobar resection for the subcentimeter pulmonary nodule. Semin Thorac Cardiovasc Surg 2005; 17(2): 128-33.

[68] Kodama K, Doi O, Higashiyama M, Yokouchi H. Intentional limited resection for selected patients with T1 N0 M0 non-smallcell lung cancer: a single-institution study. J Thorac Cardiovasc Surg 1997; 114(3): 347-53. 
[69] Yoshikawa K, Tsubota N, Kodama K, Ayabe H, Taki T, and Mori T. Prospective study of extended segmentectomy for small lung tumors: the final report. Ann Thorac Surg 2002; 73(4): 1055-8.

[70] Fibla Alfara JJ, Gomez Sebastian G, Farina Rios C, Carvajal Carrasco A, Estrada Salo G, Leon Gonzalez C. Lobectomy versus limited resection to treat non-small cell lung cancer in stage I: a study of 78 cases. Arch Bronconeumol 2003; 39(5): 217-20.

[71] Nonaka M, Kadokura M, Yamamoto S, et al. Tumor dimension and prognosis in surgically treated lung cancer: for intentional limited resection. American Journal of Clinical Oncology 2003; 26(5): 499-503.

[72] Koike T, Yamato Y, Yoshiya K, Shimoyama T, and Suzuki R. Intentional limited pulmonary resection for peripheral T1 N0 M0 small-sized lung cancer. J ThoracCardiovasc Surg 2003; 125(4): 924-8.

[73] Koike T, Yamato Y, Yoshiya $\mathrm{K}$, et al. Criteria for intentional limited pulmonary resection in cT1N0M0 peripheral lung cancer. Jpn J Thorac Cardiovasc Surg 2003; 51(10): 515-9.

[74] El-Sherif A, Gooding WE, Santos R, et al. Outcomes of sublobar resection versus lobectomy for stage I non-small cell lung cancer: a 13-year analysis. Ann Thorac Surg 2006; 82(2): 408-15.

[75] Takizawa M, Oda M, Ohta $\mathrm{Y}$, et al. Perioperative targeting brachytherapy for lung cancer invading the chest wall. Kyobu Geka 2004; 57(13): 1198-201.

[76] Hu J, Zhang C, and Sun L. Localization of small pulmonary nodules for videothoracoscopic surgery. ANZ.J.Surg. 2006; 76(7): 649-51.

[77] Ciriaco P, Negri G, Puglisi A, Nicoletti R, Del Maschio A, Zannini P. Video-assisted thoracoscopic surgery for pulmonary nodules: rationale for preoperative computed tomography-guided hookwire localization. Eur J Cardio-Thorac Surg 2004; 25(3): 429-33.

[78] Lenglinger FX, Schwarz CD, Artmann W. Localization of pulmonary nodules before thoracoscopic surgery: value of percutaneous staining with methylene blue. AJR Am J Roentgenol 1994; 163(2): 297-300.

[79] Powell TI, Jangra D, Clifton JC, et al. Peripheral lung nodules: fluoroscopically guided video-assisted thoracoscopic resection after computed tomography-guided localization using platinum microcoils. Ann Surg 2004; 240(3):481-8

[80] Wicky S, Mayor B, Cuttat JF, Schnyder P. CT-guided localizations of pulmonary nodules with methylene blue injections for thoracoscopic resections. Chest 1994; 106(5): 1326-8.

[81] McConnell PI, Feola GP, Meyers RL. Methylene blue-stained autologous blood for needle localization and thoracoscopic resection of deep pulmonary nodules. J Pediatr Surg 2002; 37(12): 1729-31.

[82] Suzuki K, Nagai K, Yoshida J, et al. Video-assisted thoracoscopic surgery for small indeterminate pulmonary nodules: indications for preoperative marking. Chest $1999 ; 115(2)$ : 563-8.

[83] Hazelrigg SR, Nunchuck SK, and LoCicero J, III. Video Assisted Thoracic Surgery Study Group data. Ann Thorac Surg 1993; 56(5): 1039-43.

[84] Mack MJ, Shennib H, Landreneau RJ, Hazelrigg SR. Techniques for localization of pulmonary nodules for thoracoscopic resection. Journal of Thoracic \& Cardiovascular Surgery 1993; 106(3): 550-3.

[85] Cleary K, Freedman M, Clifford M, Lindisch D, Onda S, Jiang L. Image-guided robotic delivery system for precise placement of therapeutic agents. J Control Release 2001; 74(1-3): 363-8.

[86] Wesarg S, Firle EA, Schwald B, Seibertk H, Zogal P, and Roeddiger S. Accuracy of needle implantation in brachytherapy using a medical AR system: a phantom study. Proceedings of SPIE Medical Imaging: Visualization, Image-Guided Procedures, and Display 2004; 5367:341-52.

[87] Zhang H, Banovac F, Lin R, et al. Electromagnetic tracking for abdominal interventions in computer aided surgery. Comput Aided Surg 2006; 11(3): 127-36.

[88] Zhang H, Banovac F, Glossop N, and Cleary K. Two-stage registration for real-time deformable compensation using an electromagnetic tracking device. Int Conf Med Image Comput Comput Assist Interv 2005; 8(Pt 2): 992-9.

[89] Schweikard A, Glosser G, Bodduluri M, Murphy MJ, Adler JR. Robotic motion compensation for respiratory movement during radiosurgery. Comput Aided Surg 2000; 5(4):263-77.

[90] Klein, GJ, Reutter BW, Huesman RH. 4D affine registration models for respiratory-gated PET. Nuclear Science Symposium; 2000 October 15-20; Lyon, France. 2: 15/41-15/45.
[91] Pitiot A, Malandain G, Bardine E, Thompson PM. Piecewise affine registration of biological images. Proceedings of Second International Workshop on Biomedical Image Registration (WBIR 2003); 2003/6.

[92] Lewis C, Bickhram M, Yu E, Wei Z, Hornblower V, Malthaner R. Feasibility of 3D ultrasound guided brachytherapy for lung cancer using a porcine lung tumour model. Medical Physics. 2006/July/15; 33(7): 2675 Abstract.

[93] Hoskins MW, Chang L, Kong H, and Hammerman MB. Brachytherapy instrument and methods. United States Patent Number: 6,752,753 2002 April.

[94] Wei Z, Wan G, Gardi L, Mills G, Downey D, and Fenster A. Robot-assisted 3D-TRUS guided prostate brachytherapy: system integration and validation. Med Phys. 2004; 31(3): 539-548.

[95] Bassan H, Hayes T, Patel RV, Moallem M. A novel manipulator for 3D ultrasound-guided percutaneous Needle Insertion. IEEE International Conference on Robotics \& Automation; 2007 April 10-4; Rome, Italy.

[96] Bassan H, Patel RV, Moallem M. A novel manipulator for percutaneous needle insertion: design and experimentation. IEEE/ASME Transactions on Mechatronics 2009; 14: 746-61.

[97] Maurin B, Piccin O, Bayle B, et al. A new robotic system for CTguided percutaneous procedures with haptic feedback. Computer Assisted Radiology and Surgery; 2004 June. International Congress Series; 1268: 515-20.

[98] Yanof J, Bauer C, and Wood B. Tactile feedback and display system for CT-guided, robot-assisted percutaneous procedures. Computer Assisted Radiology and Surgery; 2004 June. International Congress Series; 1268: 521-6.

[99] Abolhassani N, Patel RV. Teleoperated master-slave needle insertion. International Journal of Medical Robotics and Computer Assisted Surgery 2009; 5: 398-405.

[100] Hong J, Dohi T, Hashizume M, Konishi K, Hata N. An ultrasounddriven needle-insertion robot for percutaneous cholecystostomy. Phys Med Biol 2004; 49(3): 441-55.

[101] Abolhassani N, Patel RV, Moallem M. Needle insertion into soft tissue: A survey. Med Eng Phys 2006; 29(4): 413-31.

[102] Abolhassani N, Patel RV, Moallem M. Control of soft tissue deformation during robotic needle insertion. Minim Invasive Ther Allied Technol 2006; 15(3): 165-76.

[103] Abolhassani N, Patel RV, Ayazi F. Minimization of needle deflection in robot-assisted percutaneous therapy. International Journal of Medical Robotics and Computer Assisted Surgery 2007; 3: $140-8$

[104] Trejos AL, Mohan S, Bassan H, et al. An Experimental Test Bed for Robotics-Assisted Image-Guided Minimally-Invasive Lung Brachytherapy. 2007 IEEE/RSJ International Conference on Intelligent Robots and Systems (IROS'07), 2007 Oct 29-Nov 2; San Diego, California; pp. 392-7.

[105] Trejos AL, Lin AW, Pytel MP, Patel RV and Malthaner RA. Robot-assisted minimally invasive lung brachytherapy. International Journal of Medical Robotics and Computer Assisted Surgery 2007; 3(1): 4-51.

[106] Trejos AL, Lin AW, Mohan S, et al. MIRA V: an integrated system for minimally invasive robot-assisted lung brachytherapy. IEEE International Conference on Robotics and Automation; 2008 May 19-23; Pasadena, California. pp. 2982-7.

[107] Trejos AL, Patel RV, Malthaner RA. A device for robot-assisted minimally-invasive lung brachytherapy. IEEE International Conference on Robotics and Automation 2006 May 15-19; Orlando, FL. pp. 1487-92.

[108] Pytel M. M.E.Sc. Thesis. The development of an image based navigation system for use in interstitial lung brachytherapy. 2005/12/1. University of Western Ontario.

[109] Hornblower V, Gardi L, Yu EW, Battista JJ, Fenster A, Malthaner RA. Intraoperative 3D ultrasound imaging of a lung tumour. Canadian Journal of Surgery. 2004/August/15; 47(Supplement):30 Abstract \# 78.

[110] Hornblower V, Gardi L, Yu E, Battista JJ, Fenster A, Malthaner RA. Development of a lung tumour model for validating 3dimensional thoracoscopic ultrasound imaging. Canadian Journal of Surgery. 2005/August/15; 48(Supplement):32 Abstract \# 89.

[111] Hornblower V, Yu E, Fenster A, Battista JJ, Malthaner RA. Performance evaluation of thoracoscopic 3D ultrasound imaging in an in vitro porcine model. Canadian J Surg 2006/August/15; 49(Supplement):28 Abstract \# 72. 
[112] Hornblower V. M.E.Sc. Thesis. Three-dimensional ultrasound imaging of lung tumours. 2005/10/30. University of Western Ontario.

[113] Malthaner RA., Yu E, Battista JJ, Blake C, Downey D, Fenster A. Robotically assisted ultrasound image guided interstitial lung brachytherapy in a porcine model. International Society for Computer Aided Surgery Computer Assisted Radiology and Surgery. 19th International Congress and Exhibition; Poster. Berlin, Germany.

[114] Lin AW, Trejos AL, Patel RV, Malthaner RA. Robot-Assisted Minimally Invasive Brachytherapy for Lung Cancer. Telesurgery,
Kumar S. \& Marescaux J. editors 1st Editions 2008/Jan/15 Chapter 4, pp. 37-56.

[115] Ma G, Pytel M, Trejos AL, et al. Zeus robot assisted thoracoscopic brachytherapy: Zeus $v s$ VATS $v s$ manual seed implantation. Minimally Invasive Robotic Association: 1st Worldwide Meeting; Poster. Innsbruck, Austria.

[116] Ma G, Pytel M, Trejos AL. et al. Robot-assisted thoracoscopic brachytherapy for lung cancer: comparison of the ZEUS robot, VATS, and manual seed implantation. Computer Aided Surgery 2007; 12(5): 270-7. 